\title{
Idade penal no jornalismo de referência: os sentidos centrais na cobertura do debate sobre redução da maioridade penal
}

Anelise Schütz Dias

Resumo: O artigo se vale de uma perspectiva discursiva para compreender os fenômenos que envolvem jornalismo e segurança pública. Para tal, analisamos os núcleos de sentido que mais apareceram no discurso jornalístico de referência no debate sobre redução da maioridade penal, estimulado, dentre outros fatores, pela votação da PEC 171/1993. A observação foi realizada no período de 01 de junho a 05 de julho de 2015 nos jornais Folha de S. Paulo, O Globo e O Estado de S. Paulo. As sequências discursivas extraídas de 60 reportagens apontaram para quatro núcleos de sentido principais: disputa política/barganha/alianças temporárias; falhas no ECA/no sistema socioeducativo; violência dos "menores" x violência contra os "menores"; e ausência de dados nacionais para o debate sobre a redução da idade penal.

Palavras-Chave: jornalismo; segurança pública; redução da maioridade penal; análise do discurso.

Abstract: Penal age in reference press: the central meanings in the coverage of the debate on the reduction of penal majority - This paper adopts a discursive perspective to understand the phenomena that involves journalism and public safety. It analyses the meaning cores that have most appeared in the journalistic discourse about the debate on the reduction of the penal age, stimulated, among other factors, by the vote of the PEC 171/1993. The observation was performed during the period from June $1^{\text {st }}$ to July $5^{\text {th }} 2015$ in the newspapers Folha de S. Paulo, O Globo and O Estado de S. Paulo. The discursive sequences extracted from 60 reports pointed to four cores of meaning: political dispute/bargaining/temporary alliances; failure in the ECA (Legal Statute of Minors)/socio-educational system; violence of "minors" vs. violence practiced against "minors"; and the absence of national data for the debate on the reduction of the age of criminal responsibility.

Keywords: journalism; public safety; reduction of the age of criminal responsibility; discourse analysis. 


\section{Introdução}

Grandes temas de discussão social e política reaparecem ciclicamente na agenda pública, sobretudo após algum evento desencadeante ou momento-crise, ocasionando intensos debates geradores de sentidos sociais. Desde que a nova composição do Congresso Nacional foi estruturada pós-eleições de 2014, já havia rumores de que a imputabilidade penal para maiores de 16 anos seria uma dentre as pautas prioritárias, sob a justificativa de redução dos índices de vitimização por criminalidade e por violência.

Observando a cronologia dos fatos, seria possível inferir dois dos prováveis eventos desencadeantes para que, de fato, a redução da maioridade penal, representada pela PEC $171 / 1993^{1}$, entrasse em pauta e fosse à votação no plenário da Câmara: a comoção referente à morte do médico Jaime Gold, de 56 anos, vítima de latrocínio praticado por dois adolescentes na Lagoa Rodrigo de Freitas, no Rio de Janeiro, no dia 19 de maio de 2015, e o choque frente ao horror de um estupro coletivo de quatro adolescentes, seguido de agressão física grave, cometido por quatro menores e um adulto, em Castelo do Piauí, município a 190 km de Teresina, em 27 de maio de 2015. Ambos os crimes e seus desdobramentos foram amplamente noticiados nas semanas subsequentes, e outros casos semelhantes, que aconteceram em períodos anteriores, também voltaram à discussão. Diante disso, a forma de punir os adolescentes em conflito com a lei e a efetividade das medidas socioeducativas existentes retornaram à pauta do jornalismo.

Neste artigo, analisamos os sentidos sobre redução da idade penal e segurança pública, postos em circulação pelo discurso jornalístico de referência. Esse é um recorte de uma investigação maior, que tem como tema o discurso jornalístico sobre redução da maioridade penal nos jornais de referência Folha de S. Paulo, O Globo e O Estado de S. Paulo, em suas versões impressas. Por jornais de referência compreendemos aqueles consolidados como formadores de opinião, devido à credibilidade adquirida ao longo de sua história e por serem destinados a um público qualificado, sendo essas publicações equivalentes aos quality papers (AMARAL, 2006; MORETZSOHN, 2014). Neste recorte, buscamos demonstrar quais núcleos de sentido principais apareceram na cobertura a partir da leitura qualificada do corpus de pesquisa. Foram eles: disputa política/barganha/alianças temporárias; falhas no ECA/no sistema socioeducativo; violência dos "menores" x violência contra os "menores"; e ausência de dados nacionais para o debate sobre a redução da idade penal.

\section{Crime, violência e jornalismo}

Partimos do pressuposto de que o jornalismo é um lugar de circulação e de produção de discursos sociais (BENETTI, 2006). Por discurso entendemos a prática da linguagem,

1 De acordo com a ementa publicada no site oficial da Câmara de Deputados, a PEC 171/1993: "Altera a redação do art. 228 da Constituição Federal (imputabilidade penal do maior de dezesseis anos)". A proposta foi discutida, arquivada e desarquivada diversas vezes, nos últimos 22 anos, o que mostra seu caráter cíclico. Foi apresentada em 19/08/1993, por Benedito Domingos (PP-DF). 
a palavra em movimento, atravessada pela história, pela ideologia e pelo inconsciente, que constitui os sujeitos (PECHÊUX, 1990; ORLANDI, 2005). Por sua inserção e legitimidade social, entendemos que o jornalismo participa da construção simbólica da experiência social dos indivíduos, podendo ser compreendido como uma instituição (FRANCISCATO, 2014). Como instituição, é produtor de certo conhecimento (MEDITSCH, 1992; 2002), que não está livre das contradições políticas, ideológicas ou filosóficas que atravessam a sociedade de classes (GENRO FILHO, 1987).

Entendemos também que o jornalismo dita padrões de normalidade e atua no sentido de promover um suposto consenso de quais condutas seriam adequadas ou não ao modelo de sociedade vigente (BENETTI, 2008; PARK, 2008). E que o noticiário sobre crime e violência reitera, muitas vezes, o sentido de que vivemos uma nova e crescente crise de segurança pública, utilizando como recurso discursivo o apagamento de um passado de conflitos (BATISTA, 2002), que contribui para a formação de uma memória discursiva que é acionada cada vez que um novo crime hediondo choca e horroriza a sociedade.

Por segurança pública entendemos "a estabilização universalizada, no âmbito de uma sociedade em que vigora o Estado Democrático de Direito, de expectativas positivas a respeito das interações sociais - ou da sociabilidade, em todas as esferas da experiência individual" (SOARES, 2011). Acreditamos que a argumentação do jornalismo, em termos de uma crise de segurança pública (PORTO, 2008), possa ser uma das explicações para a adesão da sociedade, representada por pesquisas de opinião e por manifestações individuais e coletivas mediadas pelo jornalismo, a determinadas políticas. Em nome da segurança e da contenção do risco, por exemplo, a restrição/supressão de alguns direitos e garantias fundamentais nos parece ser aceita como forma de antecipação frente a um sofrimento evitável (VAZ, CARVALHO E POMBO, 2005). E, se a restrição/supressão desses direitos é destinada ao outro, essa adesão parece ainda mais fácil (CARVALHO, 2006).

Reconhecemos também que os veículos jornalísticos, nas democracias contemporâneas, se estabelecem como alguns dos principais produtores e reprodutores de sentidos sociais. E que, por isso, quando o tema é mídia e segurança pública, é preciso que estejamos atentos à relação paradoxal que se estabelece entre esses dois âmbitos, já que eles se interligam de forma "[...] tensa e contraditória, por vezes; consensual e cúmplice, por outras" (PORTO, 2008, p. 214-215).

Nessa negociação também podemos acrescentar a política, que se vale da visibilidade promovida pela cobertura, de modo que temas como crime e violência são utilizados para alavancar carreiras políticas, impor perdas aos opositores e também alterar legislações conforme interesses específicos. Tais ações são características do jogo político, que compreende "uma ampla gama de interações entre as forças políticas que inclui comportamentos como acordo, articulação, acerto, barganhas, alianças, retaliações, composições e compensações, de que a esfera política é pródiga" (GOMES, 2004, p. 83). 
Para Rolim (2006, p. 190), ao cobrir temas que tratam de crime e violência, há uma forte tendência por parte do noticiário de realizar um movimento que afasta a singularidade de eventos dramáticos das dimensões do universal e do particular, interrompendo a relação dialética intríseca às três dimensões de que fala Genro Filho (1987). Dessa forma, o fato relatado aparece como se emancipado de suas circunstâncias contextuais, como se carente de referência externa. Porém, esse silêncio das causas frente aos efeitos, do não reconhecimento da inscrição do fato relatado em um fenômeno, que lhe é anterior e exterior, são estratégias discursivas que produzem sentido. Para Rolim, "o sentido produzido quando o crime violento emerge como um fenômeno desconhecido só pode ser um: ele é a expressão da maldade dos indivíduos" (ROLIM, 2006, p. 191).

Quando o fenômeno aparece de forma independente, ele se resume ao ato infracional em si e aos seus autores. $\mathrm{E}$, muitas vezes, à dor das vítimas ou das pessoas próximas a elas (ROLIM, 2006). A história de vida dos infratores e de seus familiares, quando encontra espaço no noticiário, ainda é de forma insuficiente: "como essa figura não tem história, nem qualquer outro atributo que revele sua condição humana e sua personalidade contraditória, ela mesmo termina sendo reduzida e definida por aquela possibilidade perigosa e detestável" (ROLIM, 2006, p. 191). Não tendo história nem rosto, a complexidade dos que cometem atos infracionais fica, na maioria das vezes, reduzida a estereótipos criminais de fácil assimilação, que podem ser percebidos diariamente no tratamento dado às notícias sobre crime e violência:

A difusão dos estereótipos dos criminosos como pertencentes às classes sociais mais vulneráveis da população; a ideia de criminalidade vinculada a crimes contra o patrimônio, ligado à vida e também ao tráfico de drogas; a percepção social da vítima de crime como sendo a mulher branca de classe média: todos esses estereótipos reforçam a ação seletiva do sistema penal, legitimando-o. (BUDÓ et al, 2014, p. 8).

Os jovens pobres, negros e periféricos, que reúnem as características do estereótipo criminal de que fala Budó et al (2014), são as principais vítimas de homicídios registrados no Brasil, conforme os dados do Mapa da Violência de 2014, e estão situados nos dois extremos da violência. Com a aprovação da PEC 171/1993, a Câmara dos Deputados demonstra preocupação com um dos extremos, o dos jovens cometendo violência, mas desconsidera a por eles sofrida.

Já as vozes dissonantes, de parlamentares contrários à PEC, afirmam que um Estado que não é capaz de acolher os jovens também não pode puni-los. O que prevalece no debate no âmbito político, mediado pelo jornalismo, porém, são dizeres que reforçam o estereótipo do jovem violento, agressivo e ameaçador e, sobretudo, aos 16 anos, amplamente consciente de seus atos. Estereótipos que reforçam o senso comum criminológico sobre o qual reflete Moretzsohn (2014) e influenciam na criação de leis e normas cada vez mais repressivas, destinadas, sobretudo, aos grupos sociais mais vulneráveis. 
Por senso comum criminológico, Moretzsohn compreende o apelo ao recrudescimento da lei penal, baseado em "uma série de lugares-comuns reveladores: manifestações exacerbadas

[...] traduzidas em prescrições legislativas e sugestões de penas corporais de sabor medieval, ao mesmo tempo em que deploram a ineficácia ou a lentidão do Judiciário e o conseqüente apelo à ação direta, com o apoio ao linchamento" (MORETZSOHN, 2014, p. 87).

Sendo reforçados os lugares-comuns do senso comum criminológico, apontados por Moretzsohn (2014), o jornalismo opera uma constante e cotidiana legitimação do sistema penal em seus discursos (BUDÓ, 2006). Ainda que não deixe de abordar as falhas deste sistema, o toma como um mal necessário, que pode ser corrigido e aprimorado, se endurecido - aparecendo, assim, a pena como rito sagrado de resolução dos conflitos (BATISTA, 2002).

\section{Análise dos sentidos}

Utilizamos a Análise de Discurso da corrente de Pechêux na observação do objeto empírico, que é composto por 105 edições dos jornais Folha de S. Paulo², O Globo ${ }^{3}$ e O Estado de S. Paulo ${ }^{4}$ de 01 de junho a 05 de julho de 2015. Delas, foram extraídos 169 textos de diferentes gêneros que trataram da redução da idade penal ${ }^{5}$. Do total de textos, foram escolhidas 60 reportagens, 20 de cada veículo, das quais foram extraídas as sequências discursivas (trechos significativos) que tratam de nossa problemática. Ao todo, foram encontrados 107 trechos - Folha de S. Paulo (39), O Globo (34) O Estado de São Paulo (34) - que apontaram para quatro núcleos de sentido principais nesta cobertura: a) disputa política/barganha/alianças temporárias (47,66\%); b) falhas no ECA/no sistema socioeducativo (28,03\%); c) violência dos "menores" $x$ violência contra "menores" $(14,95 \%)^{6}$; d) ausência de dados nacionais para o debate sobre a redução da idade penal (9,3\%).

O primeiro núcleo de sentido é o que representa a disputa política/barganha/alianças temporárias. É nele que estão reunidas as SDs que representam as disputas e a competição entre as forças presentes na esfera política, com a mediação do jornalismo (GOMES, 2004).

2 A Folha de S. Paulo é um jornal de periodicidade diária pertencente ao Grupo Folha e ocupa a $3^{\mathrm{a}}$ posição no ranking dos maiores jornais de circulação paga no Brasil, com a média 189.254 exemplares/dia, segundo dados da Associação Nacional dos Jornais (2015).

3 O Globo é um jornal de periodicidade diária, que pertence ao Grupo Globo, maior conglomerado midiático brasileiro, e ocupa a $2^{\mathrm{a}}$ posição no ranking dos maiores jornais de circulação paga no Brasil (impresso e online), com a média de 193.079 mil exemplares/dia, segundo dados da Associação Nacional dos Jornais (2015).

4 O Estado de S. Paulo ("Estadão") é um jornal pertencente ao Grupo Estado e ocupa a $4^{\circ}$ posição no ranking dos maiores jornais de circulação paga no Brasil com a média de 157.761 exemplares/dia, segundo dados da Associação Nacional dos Jornais (ANJ) para o ano de 2015. De 2014 até agora, assim como a Folha de S. Paulo e O Globo, o Estadão teve sua tiragem diária reduzida drasticamente, embora tenha mantido a mesma posição no ranking.

5 Na Folha foram coletados 63 textos e o tema foi verificado em 10 capas (7 chamadas e 3 manchetes). Em O Globo, 68 textos e apareceu em 7 capas ( 3 chamadas e 4 manchetes). E, por fim, no Estadão, 37 textos foram colhidos e o tema esteve presente em 9 capas (8 chamadas e 1 manchete).

6 Utilizamos "menor" junto de aspas para designar os adolescentes em conflito com a lei como referência ao modo como o termo é mais comumente utilizado no jornalismo analisado e por discordarmos do termo, que reforça estereótipos, sobretudo de jovens periféricos. 
Esse sentido pode ser observado, em sua operação discursiva, nos trechos ilustrativos a seguir. Os termos que buscam sedimentar o sentido estão em negrito:

A declaração de Alckmin foi avaliada por aliados como uma tentativa do governador nacionalizar seu nome para a eleição presidencial de 2018. Pessoas próximas a Aécio Neves (PSDB) acreditam que a intenção de Alckmin é rivalizar com o mineiro, outro nome para a disputa. ("Cunha admite votar proposta de Alckmin para menores", Folha, 6 de junho).

Numa tentativa de evitar ser derrotado no tema, o Governo anunciou apoio a projeto do senador José Serra (PSDB-SP) que não propõe a redução da maioridade penal, mas, sim, a ampliação para até dez anos do tempo de internação de menores infratores. "PMDB e PSDB fazem acordo na Câmara pela redução", O Globo, 17 de junho).

O PMDB fez acordo com o PSDB, DEM, PSB, Solidariedade e mais alguns nanicos em defesa de uma proposta inspirada na apresentada pelo senador Aloysio Nunes Ferreira (PSDB-SP), que condicionava a redução da maioridade aos 16 anos para os casos de crimes hediondos desde que pedida pelo Ministério Público e aprovada por um juiz. ("PMDB e PSDB fazem acordo na Câmara pela maioridade; Senado analisada o projeto", Estadão, 17 de junho).

As sequências-exemplo revelam que há pelo menos quatro embates em curso, representados no discurso jornalístico dos três jornais: entre Planalto e Congresso; entre PT e PSDB; entre esquerda e direita, já que os jornais caracterizam, em vários momentos, a manutenção da idade penal como uma pauta histórica da esquerda brasileira; e a disputa intrapartidária corrente no PSDB, que está polarizada em torno dos potenciais candidatos à Presidência da República nas eleições de 2018.

Percebemos que há uma disputa bastante acirrada em curso, que envolve interesses de blocos políticos, mas também pessoais, ainda que atravessados por questões políticopartidárias, que justificam a formação de alianças, a utilização de estratégias e de barganhas para atingir fins específicos, como, por exemplo, a nacionalização de nomes para as próximas eleições. Isso nos permite compreender que, quando transformada em disputa política, como forma de apenas impor perdas aos opositores ou barganhar garantias e privilégios, a política pública não se volta para a necessidade da contenção da violência e da criminalidade, ainda que essa seja a justificativa apresentada à sociedade pelos políticos. Embora o jornalismo de referência tenha construído outros sentidos verificáveis, além do da disputa política, o fato de ser esse o principal não é diretamente questionado na cobertura, dada a assustadora naturalização de que pautas de grande impacto social sejam utilizadas como estratégias do jogo político.

O segundo núcleo de sentido que encontramos trata das falhas no Estatuto da Criança e do Adolescente e/ou no sistema socioeducativo e contempla dizeres como os que afirmam que o Estatuto promoveria certa impunidade a adolescentes, já que seria fraco e o tempo de internação máxima (que o grupo contrário à redução propõe expandir) dificilmente tem 
sido cumprido. Esse sentido também aponta para a falta de investimento e de infraestrutura nas unidades socioeducativas, em desobediência ao que é previsto pelo ECA:

O ECA é fraco, não pune, tanto é que, após atingir a maioridade, esse marginal sai com a ficha limpa independentemente dos crimes bárbaros que tenha praticado", afirmou Capitão Augusto (PR-SP). ("Em decisão apertada, Câmara rejeita a redução da maioridade penal", Folha, 01 de junho).

É gritante o descompasso entre o sistema socioeducativo previsto na legislação e a realidade. Além do desrespeito ao Estatuto da Criança e do Adolescente (ECA), unidades para infratores do país inteiro ignoram as Regras Mínimas das Nações Unidas para Proteção dos Jovens em Privação da Liberdade. Uma delas é a que determina a separação dos jovens por porte físico, o que evita a violência, inclusive sexual, entre os reeducandos. ("Apenas 30\% das unidades prisionais separam jovens pelo porte físico", Globo, 21 de junho).

A separação dos adolescentes por porte físico, que seria uma medida que diminuiria a violência dentro dos espaços socioeducativos, inclusive sexual, e limitaria o contato entre os que cometeram crimes hediondos e os autores de infrações menores, por exemplo, é uma das prescrições do ECA e da ONU que não são obedecidas. Isso ocorre também pela falta de infraestrutura e de espaço físico nas unidades socioeducativas que afirmam a superlotação desses espaços.

As carências infraestruturais nas instituições socioeducativas não dizem respeito apenas aos espaços físicos, mas também à falta de equipamentos e de materiais para as atividades educativas, o que reflete nos processos de ressocialização, já que, sem educação formal ou um ensino profissionalizante, ao sair das instituições, encontram dificuldade de se (re)inserirem no mercado de trabalho. O desinvestimento do Estado no acolhimento/reeducação dos adolescentes em conflito com a lei aparece em sequências discursivas que apontam para cortes no orçamento previsto e atrasos nos repasses que impossibilitam a continuidade de programas socioeducativos.

Ainda pela falta de infraestrutura, os espaços destinados aos adolescentes, que deveriam obedecer aos parâmetros firmados pelo ECA e pelas Regras Mínimas das Nações Unidas para Proteção dos Jovens em Privação da Liberdade, transformam-se em espaços muito semelhantes aos presídios em que estão internados os adultos: falta saneamento básico, há superlotação e o contingenciamento de despesas afeta, inclusive, o transporte desses adolescentes para as audiências, dentre uma série de outras questões igualmente preocupantes, que são apresentadas nas reportagens observadas. A falta de condições para a educação desses adolescentes e, sobretudo, de profissionalização, está dentre os fatores que dificultam a ressocialização após o cumprimento das penas e a inclusão no mercado de trabalho formal, o que está ligado também à reincidência.

O discurso jornalístico aponta, portanto, para o sentido nuclear de que o ECA não 
é obedecido, no que tange às punições e à infraestrutura socioeducativa, já que, muitas vezes, não contempla as necessidades dos adolescentes, como o direito à educação e à ressocialização. Também demonstra que sua aplicação, ainda que parcial, tem se mostrado pouco eficaz na proteção desses adolescentes contra a violência, já que estes permanecem nos dois extremos da violência, sendo vítimas e algozes. É importante situar, ainda, que este sentido constrói a ideia de que a violência contra os jovens ocorre não apenas quando se refere à integridade física e moral, mas também que há violência contra esse grupo toda vez que o Estado falha em "reeducá-los". Reconhecer isso nos leva ao terceiro núcleo de sentido, violência dos "menores" x violência contra os "menores", que trata dos jovens, nos dois extremos da violência:

Três apreensões por tráfico, quatro roubos à mão armada e um homicídio constam na ficha do adolescente. Com 15 anos, de pele branca e fala calma, ele já passou por quatro centros de internação de menores infratores entre o Distrito Federal e o Goiás e hoje está numa unidade em Formosa, no interior do DF. Ele lista a diferença entre as unidades com termos comuns no sistema penitenciário: onde havia "boi" e não vaso, qual servia a melhor "xepa" e como usou uma "teresa" para matar um colega de "barraco". O vocabulário do adolescente (referindo-se ao buraco no chão que serve como sanitário, à comida ofertada nas unidades, à corda feita de lençóis amarrados e ao alojamento que dividia com um desafeto) é um dos pontos comuns entre o sistema socioeducativo e o prisional no país. (“Unidades para menor parecem presídios", O Globo, 21 de junho).

Os crimes cometidos por adolescentes representam menos de 3\% do total de atos infracionais - quando não se leva em consideração o tráfico de drogas. Mas, novamente, foram os jovens na faixa de 16 a 18 anos que cometeram mais desses tipos de crimes, como homicídio qualificado, estupro e latrocínio: $64,8 \%$. ("Em cada dez atos infracionais em SP, 7 envolvem adolescentes de 16 a 18 anos", O Estado, 12/06/2015).

O Mapa da Violência de 2014 revela que são eles as maiores vítimas de violência no Brasil. Na faixa dos 16 aos 17 anos, os jovens representam quase 7\% das vítimas de homicídio em 2013 em toda a população. Em pouco mais de três décadas, o número de adolescentes dessa faixa etária vitimados por homicídios se multiplicou por pelo menos sete vezes. A estagnação na inclusão no sistema educacional e a dificuldade de, uma vez incluído, avançar nele, são explicações possíveis para o aumento da vulnerabilidade dos jovens e também da violência por eles praticada. Em São Paulo, como demonstra o trecho-exemplo do Estadão, ainda que os jovens tenham uma participação pequena no total de atos infracionais praticados, quando cometem crimes trata-se, principalmente, de hediondos, como homicídio qualificado, estupro e latrocínio, o que serve de justificativa para que jornal, ao longo da cobertura, defenda que é preciso endurecer os parâmetros 
de responsabilização desses jovens, como é afirmado no texto com a opinião do jornal, o editorial "Avanço Importante" (Estadão, 19/06/2015), em que parabeniza a Câmara de Deputados por recolocar o tema em pauta.

O quarto e último núcleo de sentido representa a ausência de dados nacionais para o debate sobre a redução da idade penal. Ainda que tenha aparecido apenas no jornal Folha de S. Paulo é importante pela ênfase percebida na cobertura e por sua relevância para a discussão sobre segurança pública no Brasil. Esse sentido representa a dificuldade de se realizar um levantamento nacional dos crimes e violências praticados por adolescentes em relação ao total de delitos praticados no país, já que não há um esforço comum de coleta que envolva os Estados e Municípios, nem taxas suficientes de registro e de esclarecimento de crimes no Brasil.

\begin{abstract}
Segundo especialistas em criminalidade, a falta de evidências dificulta a formulação de políticas de segurança no Brasil e turva debates como o da eventual eficácia de se reduzir a maioridade penal de 18 para 16 anos. ("Lacuna em estatísticas sobre menores infratores contrasta com outros países", Folha, 7 de junho).

Para especialistas, os governos estaduais resistem em divulgar números ligados à violência por temerem uso político dessas estatísticas. Além disso, a falta de padronização na coleta nos Estados impede a consolidação de dados nacionais.
\end{abstract} (idem, Folha, 7 de junho).

O esforço jornalístico de demonstrar a falta de dados nacionais que possam sustentar o debate sobre a segurança pública, no que tange a relação dos adolescentes com o total de atos infracionais cometidos no Brasil, permite inferir que tanto os favoráveis como os contrários à PEC 171/1993 desconhecem a realidade. Seja porque não há, portanto, uma forma de coleta de dados homogênea nem uma metodologia comum aos Estados e aos Municípios, seja por falta de vontade política ou pela pífia taxa de esclarecimentos de crimes no Brasil (menos de 10\% dos crimes são elucidados), o fato é que, ambos os lados dessa disputa, não possuem essa informação.

Quando assume essa impossibilidade e empreende um levantamento autônomo, reunindo dados de nove Estados da Federação, a Folha de S. Paulo demonstra interesse em produzir conhecimento sobre o tema para fomentar o debate ("Brasil revê maioridade penal sem ter mapa da criminalidade juvenil", Folha de S. Paulo, 07/06/2015). E admite, ainda, que os números levantados pelo jornal não podem ser comparados por terem sido coletados a partir de procedimentos diferentes, reconhecendo as limitações do trabalho jornalístico e do conhecimento por ele produzido, já que este nunca é autônomo ou original, mas sempre dependente de outras instituições, como propõe Meditsch (1992).

Sem dados que possam mensurar a criminalidade e a violência praticada por menores no total de crimes cometidos no Brasil, a retórica predominante é muito mais de contenção e de apartamento dos jovens em conflito com a lei do que de garantia de direitos fundamentais. O caráter reativo e punitivo do discurso jornalístico de referência 
converge com a maioria das políticas de segurança pública hoje aplicadas no Brasil, que atentam ao jovem apenas depois de praticado o ato infracional, quando transformados em um 'problema social'.

Como demonstrou a análise, nas edições observadas são denunciadas as falhas no Estatuto da Criança e do Adolescente, no sistema socioeducativo e a violência sofrida pelos jovens, mas, ainda assim, segue perceptível o reforço do senso comum criminológico (MORETZSOHN, 2014), de que os jovens em conflito com a lei são violentos, agressivos e responsáveis por uma parcela significativa da criminalidade e da violência, ainda que não haja dados para mensurar essa participação no total de crimes, como reconhece a Folha.

Essas observações nos levam a concluir que, mesmo reconhecendo que as falhas no sistema são geradoras de violência, o jornalismo de referência se filiou à legitimação do sistema penal e de suas atribuições (BUDÓ, 2006), que apareceram como passíveis de correção e de aprimoramento, mas não de substituição, já que a pena (ou a medida socioeducativa, no caso analisado) continua aparecendo como se fosse o rito sagrado de resolução dos conflitos (BATISTA, 2002). Por fim, embora tenha produzido certo conhecimento sobre o tema, quando traz questões que comumente não aparecem no jornalismo tradicional, como a violência sofrida pelos jovens em conflito com a lei e a insuficiência de dados para o debate de segurança pública, ainda assim, o jornalismo de referência não nos pareceu livre das contradições políticas, ideológicas e filosóficas que constituem a sociedade de classes (GENRO FILHO, 1982). Pelo contrário, ao não questionar a transformação da redução da maioridade penal em mera disputa política, com interesses pessoais e partidários conhecidos, não apenas reproduz como naturaliza aspectos da luta de classes.

\section{Considerações finais}

Neste artigo, analisamos os sentidos sobre redução da idade penal e segurança pública postos em circulação pelo discurso dos jornais Folha de S. Paulo, O Globo e O Estado de S. Paulo no mês da votação do texto da PEC 171/1993 na Câmara dos Deputados. Quatro núcleos de sentido principais estiveram presentes na cobertura no período analisado. Foram eles os da disputa política/barganha/alianças temporárias; das falhas no ECA/no sistema socioeducativo; da violência dos "menores" x violência contra os "menores"; e da ausência de dados nacionais para o debate sobre a redução da idade penal. Já os "direitos referentes à vida, à saúde, à alimentação, à educação, ao esporte, ao lazer, à profissionalização, à cultura, à dignidade, ao respeito, à liberdade e à convivência familiar e comunitária" (BRASIL, Lei 8.069, art. 4º), que são garantias constitucionais de crianças e adolescentes, tenham cometido infrações ou não, apareceram timidamente na cobertura observada, diluídos nos núcleos de sentido que apontam as falhas no sistema socioeducativo e no Estatuto da Criança e do Adolescente e no que revela que os jovens 
estão nos dois extremos da violência.

Nossa análise permitiu concluir, portanto, que o discurso do jornalismo de referência, ainda que tenha atentado às falhas no sistema responsável pelo jovem em conflito com a lei, acabou por legitimar, mais uma vez, políticas de segurança pública punitivistas e reativas, ao centralizar a ênfase em outros aspectos que não a garantia dos direitos de cidadania das crianças e adolescentes.

Anelise Schütz Dias é doutoranda do Programa de Pósgraduação em Comunicação e Informação da UFRGS e membro do Núcleo de Pesquisa em Jornalismo. Ébolsista Capes. anelisesdias@gmail.com

\section{Referências}

AMARAL, Márcia Franz. Imprensa popular é sinônimo de jornalismo popular? In: XXIX Congresso Brasileiro de Ciências da Comunicação. Brasília: UNB, 2006.

BATISTA, Nilo. Mídia e sistema penal no capitalismo tardio. Discursos sediciosos: crime, direito e sociedade. Rio de Janeiro, Ano 7, n. 12, p. 271-288, $2^{\circ}$ sem. 2002.

BENETTI, Márcia. "Jornalismo e perspectivas de enunciação: uma abordagem metodológica". Intexto: revista do mestrado da comunicação UFRGS, v.1, n.14, p.1-11, janeiro/julho de 2006. SP, 2008.

"O jornalismo como gênero discursivo". Revista Galáxia, n. 15, p. 13-28. São Paulo: PUC-

BRASIL. Constituição (1988). Constituição da República Federativa do Brasil. Brasília, DF: Senado Federal: Centro Gráfico, 1988.

BRASIL, Mapa Da Violência. 2015. Disponível em: <http://www.mapadaviolencia.org.br/pdf2015/ mapaViolencia2015_adolescentes.pdf> Acesso em: 15/08/2015.

BRASIL. Congresso Nacional. Estatuto da Criança e do Adolescente. Lei $\mathbf{n} .^{\mathbf{0}} \mathbf{8 . 0 6 9}$, de 13 de julho de 1990. Dispõe sobre o Estatuto da Criança e do Adolescente e outras providências. Diário Oficial da União, Brasília, DF, 13 jul. 1990.

BRASÍLIA (DF). Projeto de lei n.171, 19 de agosto de 1993. Altera a redação do art. 228 da Constituição Federal (imputabilidade penal do maior de dezesseis anos. Disponível em: http://imagem.camara. gov.br/Imagem/d/pdf/DCD27OUT1993.pdf\#page=10. Acesso em: 27/08/2015

BUDÓ, Marília. "Mídia e crime: a contribuição do jornalismo para a legitimação do sistema penal". Unirevista, vol.1, n.3, p. 1-14. São Leopoldo: 2006.

Mídia e controle social: da construção da criminalidade dos movimentos sociais à reprodução da violência estrutural. Rio de Janeiro: Revan, 2013. 
; LEMOS, Renato de; BONATTO, Jenifer Patrícia Fragoso; CALGARO, Júlia Marmentini. Mídia e sistema penal: a construção dos estereótipos criminais. In: VIII Mostra de Iniciação Científica da IMED, 2014. Anais da VIII Mostra de Iniciação Científica da IMED. Passo Fundo: IMED, 2014.

CARVALHO, Salo de. "Política de Guerra às Drogas na América Latina: entre o direito penal do inimigo e o Estado de exceção permanente". In: SCHMIDT, Andrei Zenkner. Novos Rumos do Direito Penal Contemporâneo. Rio de Janeiro: Lumen Juris, 2006.

FRANCISCATO, Carlos. "O Jornalismo e a Reformulação da Experiência do Tempo nas Sociedades Ocidentais". In: Brazilian Journalism Research. v.2 n.2, p. 96-123. Brasília: SBPJor, 2014.

GENRO FILHO, A. O Segredo da Pirâmide: para uma teoria marxista do jornalismo. Porto Alegre: Ed. Ortiz, 1987.

GOMES, Wilson. Transformações da política na Era da Comunicação de Massa. São Paulo: Paulus, 2004.

MEDITSCH, Eduardo. O Conhecimento do Jornalismo. Florianópolis: UFSC, 1992.

Jornalismo é uma forma conhecimento? Media \& Jornalismo, Cascais/Coimbra, v. 1, n.1, p. 9-22. Coimbra: CIMJ, 2002.

MORETZSOHN, Sylvia. "Mídia e Sistema Penal: O Senso Comum Criminológico e as Dificuldades de um Discurso à Contracorrente". In: OLIVEIRA, Rafael; BUDÓ, Marília (Orgs.). Mídia e direitos da sociedade em rede. ljuí: Ed. Unijuí, 2014.

ORLANDI, Eni. Análise de discurso: princípios e procedimentos. Campinas: Pontes, 2005.

PARK, Robert. "Notícia e poder da imprensa". In: BERGER, Christa, MAROCCO, Beatriz. A Era Glacial do Jornalismo: Teorias Sociais da Imprensa, v.2. Porto Alegre: Sulinas, 2008.

PÊCHEUX, Michel. "Delimitações inversões, deslocamentos". Cadernos de Estudos Lingüísticos, 19. Campinas: IEL/Unicamp, 1990.

PORTO, Maria Stella. "Mídia, segurança pública e representações sociais". Tempo Social, v. 21, n.2, p.211-233. São Paulo: USP, 2008.

ROLIM, Marcos. A síndrome da rainha vermelha: Policiamento e segurança pública no século XXI. Rio de Janeiro: Zahar, 2006.

SOARES, Luiz Eduardo Soares. Sobre a redução da maioridade penal. 2015. Disponível em: <http:// www.luizeduardosoares.com/? p=1281>. Acesso em 10/08/2015.

VAZ, Paulo., CARVALHO, Carolina, POMBO, Mariana. "Risco e sofrimento evitável: a imagem da polícia no noticiário do crime". E-compós - Revista da Associação Nacional dos Ppg em Comunicação, v. 4. p. 1-22, 2005. 